\title{
A vulnerabilidade da globalização financeira: reflexões sobre os impactos da pandemia coronavírus na economia global neoliberal em 2020
}

La vulnerabilidad de la globalización financiera: reflexiones sobre los impactos de la pandemia de coronavirus en la economía global neoliberal en 2020 The vulnerability of financial globalization: reflections on the impacts of the coronavirus pandemic on the neoliberal global economy in 2020 La vulnérabilité de la mondialisation financière: réflexions sur les impacts de la pandémie de coronavirus sur l'économie mondiale néolibérale en 2020

\section{Pedro Henrique Chinaglia}

\section{(2) OpenEdition}

\section{Journals}

\section{Edição electrónica}

URL: http://journals.openedition.org/espacoeconomia/17523

DOI: 10.4000/espacoeconomia. 17523

ISSN: 2317-7837

\section{Editora}

Núcleo de Pesquisa Espaço \& Economia

\section{Refêrencia eletrónica}

Pedro Henrique Chinaglia, «A vulnerabilidade da globalização financeira: reflexões sobre os impactos da pandemia coronavírus na economia global neoliberal em 2020», Espaço e Economia [Online], 20 | 2020, posto online no dia 23 dezembro 2020, consultado o 29 janeiro 2021. URL: http:// journals.openedition.org/espacoeconomia/17523 ; DOI: https://doi.org/10.4000/espacoeconomia. 17523

Este documento foi criado de forma automática no dia 29 janeiro 2021.

\section{c) (1) 8 ()}

Espaço e Economia - Revista brasileira de geografia econômica est mise à disposition selon les termes de la licence Creative Commons Attribution - Pas d'Utilisation Commerciale - Partage dans les Mêmes Conditions 4.0 International. 


\section{A vulnerabilidade da globalização financeira: reflexões sobre os impactos da pandemia coronavírus na economia global neoliberal em 2020}

La vulnerabilidad de la globalización financiera: reflexiones sobre los impactos de la pandemia de coronavirus en la economía global neoliberal en 2020 The vulnerability of financial globalization: reflections on the impacts of the coronavirus pandemic on the neoliberal global economy in 2020 La vulnérabilité de la mondialisation financière: réflexions sur les impacts de la pandémie de coronavirus sur l'économie mondiale néolibérale en 2020

\section{Pedro Henrique Chinaglia}

\section{Introdução}

1 A ordem econômica neoliberal, inaugurada no início dos anos 1980, permitiu aos Estados explorar uma das medidas de liberalização dos fluxos financeiros internacionais, de modo a se inserirem e competirem no cenário internacional. Tal estratégia foi usada, principalmente, pelos países em desenvolvimento, de modo a conseguir lucros em um curto período de tempo. Em suma, as produções nacionais não eram receptoras de grandes investimentos, sendo que seu atraso industrial dificultava colocar produtos no mercado internacional de modo a suprir a demanda do capitalismo e conseguir algum lucro.

2 Tal investimento do mercado financeiro seria uma característica da chamada globalização financeirae que se sobressaiu as produções nacionais, ou seja, a globalizaçãoprodutiva. As transações financeiras internacionais diárias seriam maiores 
do que as produções nacionais. Entretanto, diante de um mercado financeiro extremamente volátil e sensível, os Estados passaram a ter um risco maior diante de externalidades e que poderiam levar a uma fuga dos capitais, assim como uma queda nos investimentos estrangeiros.

Essa doutrina tem se mantida presente até os tempos atuais. Atualmente, ocorre uma maior transação financeira entre os agentes financeiros do que uma maior produção nas fábricas nacionais. Exposto isto, em 2020 o mundo viu um sétimo coronavírus surgir e que, em 11 de março, seria caracterizado como uma "pandemia". Tal ato deixou os países muito vulneráreis, levando a uma queda nas produções nacionais e uma fuga de capitais. Assim, mais uma vez, o mundo estaria vivendo os efeitos contágios das crises econômicas da década de 1990 e que, nos dias atuais, poderá gerar novas recessões econômicas contra globalização.

4 Exposto isto, este artigo tem como objetivo analisar como a globalização financeiraneoliberal é extremamente vulnerável a externalidades, não apenas política ou socioeconômica, mas também microbiológica. A metodologia usada será referências bibliográficas que permitirão uma análise sobre o que é e como surgiu a globalizaçãofinanceira. Posteriormente, será feito um estudo sobre as crises econômicas da década de 1990, assim como suas causas e efeitos. Por fim, será elencado a vulnerabilidade da globalizaçãofinanceira, principalmente diante do surto do Coronavírus em 2020, assim como o possível cenário de recessão econômica que seguirá nos próximos meses.

\section{A vulnerabilidade da globalização financeira: um estudo sobre os impactos da pandemia coronavírus na economia global neoliberal}

\section{A globalizaçãofinanceira}

No final dos anos 1970 ocorria uma crise do capitalismo que podia ser sentida em escala global. Anteriormente, os Estados tinham a certeza de que eram os atores principais e centrais nas reações internacionais, o que, por conseguinte, levou as governanças soberanas a moldarem suas políticas externas em um isolacionismo estatal. Tal política tinha um Estado mais intervencionista na economia e no mercado, cujo objetivo era ampliar as produções internas, pelas substituições de importações, de modo a diminuir as dependências com mercados externos.

6 É diante desta crise que Rocha e Cabral (2018) explicam que a proposta do economista inglês John Maynard Keynes, de um sistema monetário internacional que viria a ser conhecido como Keynesianismo, não estava adequada aquele cenário. 0 economista propunha algumas medidas como a desvalorização cambial; financiamento de países deficitários; restrições comerciais; intervenção do Estado na economia etc., mas que eram contraditórias ao objetivo da época que era garantir uma ordem econômica global equilibrada e um livre comércio internacional.

Deste modo, com o capitalismo desregulado pela proposta inglesa e a busca cada vez mais acentuada pela internacionalização do capital produtivo, uma nova proposta monetária internacional se fazia necessária - sendo no final de 1970, a instauração do neoliberalismo de Friedrich Hayek. Explica-se que os principais objetivos da doutrina neoliberal era reestabelecer o padrão de acumulação capitalista e recuperar o ciclo 
produtivo, trazendo como resultado a retomada do crescimento econômico (ROCHA e CABRAL, 2018).

8 Assim sendo, o neoliberalismo vai contra o controle demasiado do Estado na economia, propondo que o mesmo não deveria deixar de existir, mas que agiria apenas como regulador de conflitos. Exposto isto, o mercado seria responsável por questões técnicas e sociais que advém de interesses da sociedade, enquanto o Estado teria como foco garantir uma disciplina orçamentaria e monetária, gerando assim uma estabilidade econômica (ROCHA e CABRAL, 2018).

Em suma, a ideologia neoliberal vai impor uma desestatização da economia na qual o Estado vai intervir minimamente; uma abertura dos mercados ao comércio exterior com o objetivo de estimular a concorrência de produtos nacionais; uma estabilização financeira para atrair investimentos estrangeiros e, por fim, privatizações (ROCHA e CABRAL, 2018). Entretanto, tais medidas só foram possíveis de serem impostas porque o mundo estava passando por uma transformação e um adensamento em escala global, que ficaria conhecida como "globalização".

10 Goncalves (2018) explica que a globalização teve como berço a revolução técnico científica-informacional, na década de 1970, quando as descobertas e o desenvolvimento das áreas de telecomunicações, robótica, microeletrônica, satélites etc., integraram funcionalmente em escala mundial a estrutura de produção e de comercialização do capitalismo. Deste modo, o mundo se transformou e gerou como consequência uma queda das fronteiras políticas e econômicas, proporcionando a livre circulação de mercadorias; capitais, trabalho e produção - o que pode definir a globalização produtiva (GONCALVES, 2018).

11 Em 1990, o processo da globalizaçãoé adensado no sistema internacional, muito por conta das modificações deste último, quando o fim da guerra fria encerrou a ordem mundial bipolar, capitalista e socialista, e configurou a ordem multipolar - gerando uma internacionalização do capital e da produção, criação de blocos econômicos, integração internacional e regional etc. Muitos autores tentaram definir e mensurar o grau de complexidade do globalismo, mas sem muito sucesso. 0 fenômeno gerou uma quebra de paradigma, pois tudo o que os Estados nacionais sabiam, de repente, precisava ser repensado e adaptado, ou seja, cabiam as governanças soberanas criarem novas agendas internacionais e de políticas externas. Estratégias com diretrizes "mais do mesmo" seriam consideradas um mecanismo de ação que poderia levar ao fracasso estatal.

12 Ao mesmo tempo em que o capitalismo globalizado disponibilizou acesso a fatores exteriores, antes inacessíveis, e que pareciam ser a solução diante da crise dos anos de 1970, a vulnerabilidade dos Estados se tornou um grande risco em frente a qualquer tipo de externalidade. Deste modo, havia ficado claro que toda a sociedade internacional precisaria se alinhar e adequar ao fenômeno da globalização ao estender direitos e obrigações entre os integrantes das relações internacionais (FORNASIER e SOARES, 2020).

13 Os Estados possuem uma interdependência multilateral e pluritemática, e foi agravada pela globalização como uma de suas premissas para sobreviver, visto que dentro de uma nação soberana é impossível produzir todos os bens necessários para a sua sobrevivência no sistema internacional. Assim, Goncalves (2018) explica que diante das dependências externas, as governanças estatais precisaram rearranjar as relações internacionais de modo a conseguir vantagens e proteções econômicas, assim como 
obter lucros. Tal cenário levou a criação de diversos blocos econômicos ao redor do mundo, como a União Europeia (UE), Acordo de Livre Comércio da América do Norte (ALCA), Mercado Comum do Sul (MERCOSUL), dentre outros (GONÇALVES, 2018).

O mundo já estava interconectado e próximo, e, além disso, a criação de blocos econômicos serviu para diminuir ainda mais as distâncias dos mercados - como resposta diante das demandas do capitalismo globalizado. Assim, diante desse cenário, os Estados passariam a explorar uma nova fase da globalização que se inaugurou a partir de 1990, com a revolução tecnologia e o advento da internet, ou seja, a globalização financeira.

A globalização financeira foi um recurso a ser explorado, porque após o advento do globalização em si, Cavalcanti (2019) analisa que os anos 90 seriam caracterizados por uma década não muito positiva, pois ao mesmo tempo que os fluxos comerciais entre os Estados obtiveram um significativo crescimento, o Produto Interno Bruto [PIB] obteve um crescimento tênue. Segundo o Banco Mundial, enquanto o crescimento mundial de exportações e serviços anual em 1980 foi de 1,63\%, em 2000 o saldo foi de $11,81 \%$, ou seja, em 20 anos obteve-se um crescimento médio de 5,49\%. Em contrapartida, o crescimento anual do PIB em 1980 foi de $1,9 \%$ se comparado a 4,38\% nos anos 2000 , o que significa um crescimento médio em 20 anos de 2,91\%.

É possível definir a globalização financeira como quando ocorre uma troca de recursos financeiros entre as governanças soberanas por distâncias multicontinentais, sendo mais rápido e simplificado do que bens e serviços - devido ao uso da tecnologia e de intermediadores financeiros como bancos; investidores; corretoras; entre outros (LANE e FERRETI, 2017 APUD THORSTENSEN et all., 2019). Essa fase do processo criou um cenário em que o sistema financeiro internacional se globalizou e os agentes financeiros, assim como os blocos econômicos, se integraram por conta de objetivos comuns, ou seja, a busca pelo lucro (THORSTENSEN et all., 2019).

Thorstensen et all. (2019) ainda vai afirmar que independentemente da localização geográfica e dos recursos disponíveis do país de origem, a internacionalização dos recursos financeiros permitiu obter investimentos que poderiam ser redirecionados para qualquer tipo de empreendimento produtivo - o que está alinhado com as diretrizes do Neoliberalismo, já que incita a iniciativa privada. Não obstante, diante da crise do capitalismo, os Estados não tinham os recursos disponíveis para investir diante das demandas do capitalismo globalizado, e, assim, integrar a globalização financeira pareceu ser uma estratégia para se obter recursos financeiros a curto prazo.

Para ficar claro, Baumann et all. (2004) apud Cavalcanti (2019) elencam as diferenças entre a globalização produtiva e a globalização financeira em três processos que ambos os fenômenos geram.

1. GlobalizaçãoProdutiva:

- Internacionalização da produção;

- Acirramento da concorrência entre os Estados no Sistema Internacional;

- Integração das estruturas produtivas das economias mundiais.

1. Globalizaçãofinanceira:

- Propagação dos fluxos financeiros internacionais;

- Acirramento da concorrência entre os mercados de capitais globais;

- Aumento da integração entre os sistemas financeiros. 
19 É importante ressaltar que a globalização financeira ganhou força devido as diretrizes do neoliberalismo inaugurado no final dos anos 1970. Honório e Guerra (2012) explicam que o fenômeno teve como base as políticas de desregulamentação do câmbio que, antes fixo, agora possibilitava uma flutuação e a desregulamentação financeira na qual os Estados liberalizavam os fluxos financeiros estrangeiros. Deste modo, com a mínima intervenção dos Estados na economia, havia a liberdade do mercado em conduzir as taxas de câmbio; juros; investimentos diretos estrangeiros; etc., com o objetivo de conseguir o sustento da soberania nacional.

De acordo com Thorstensen et all. 2019, a desregulamentação cambial e das finanças elevou o sistema financeiro a um nível tão grande, que as transações financeiras internacionais vêm aumentado diariamente desde os anos 1990, promovendo uma maior integração dos mercados e do mundo entre si. Reforça-se ainda que tal fato pode ser observado quando o Banco de Compensações Internacionais [BCI] compara as transações de moedas mundiais, cuja liquidez diária em 1973 era de 15 bilhões de dólares e em 2016 era de 5,06 trilhões de dólares (THORSTENSEN et all. 2019)

21 É diante dessa liquidez diária que organizações econômicas e financeiras, de alcance transnacional, passaram a integrar o mundo globalizado, como o Fundo Monetário Internacional [FMI], Banco Mundial [BM], e Organização Mundial do Comércio [OMC] (Rocha e Cabral, 2018). Explica-se que tais organizações teriam como objetivo redefinir a economia global e reconfigurar as políticas públicas, ou seja, administrar as relações rnternacionais de caráter financeiras (ROCHA e CABRAL, 2018).

Conforme exposto anteriormente, apesar de o PIB nos anos 1990 não ter obtido, em um primeiro momento, um crescimento exorbitante, não é possível negar que não havia uma reação econômica positiva acontecendo. Deste modo, de acordo com os dados expostos, a Globalizaçãohavia possibilitado certas diretrizes para que os Estados pudessem reagir diante da crise do capitalismo que assolava o mundo por volta de 1970.

23 As Nações não mais precisariam ficar isoladas no mundo, sendo que poderiam suprir suas necessidades comerciais e econômicas a partir da criação de relações multilaterais com outros países em diferentes escopos geográficos. 0 mundo globalizado havia criado os meios para que essas relações se consolidassem, permitindo uma troca de serviços; bens; conhecimentos; capitais; etc., muito rapidamente e a custos baixos. Além disso, mais do que atrair investimentos através da globalização produtiva, os fluxos financeiros também poderiam fazer parte das Relações Internacionais, o que poderiam trazer expressivos benefícios econômicos.

\section{O efeito contágio das crises econômicas da década de 1990 e a vulnerabilidade da Globalizaçãofinanceira}

24 O Neoliberalismo teve os Estados Unidos [EUA] e a Inglaterra como os países que inauguraram a nova ordem econômica mundial, ou seja, as diretrizes estavam alinhadas para os países centrais, ou seja, os desenvolvidos. Deste modo, no final do século XX, as grandes potências mundiais voltaram a atenção para os países em desenvolvimento e sua real situação.

25 Um dos renomados autores que analisou a real situação da América Latina [AL], diante do Neoliberalismo a partir dos anos 1980, foi o economista Luiz Carlos Bresser-Pereira (1998), que explica que as assimetrias políticas e socioeconômicas latino americanas, se 
comparado aos países desenvolvidos, eram massivas. Os países do Cone-Sul já possuem um histórico que os levaram a uma estagnação desenvolvimentista e um aumento contínuo de sua dependência externa, o que, por conseguinte, os conduziram a integrarem o mundo globalizado neoliberal sem ao menos se darem conta de como proceder adequadamente (BRESSER-PEREIRA, 1998).

26 Bresser-Pereira (1998) elenca que tal cenário de subdesenvolvimento latino americano foi agravado pelos antecedentes históricos como as ditaduras militares da década de 1960 e que colocaram em xeque as democracias nacionais. Com a redemocratização dos países do Cone-Sul nos anos 1980, os governos militares deixaram como legado: isolacionista estatal; medidas protecionistas econômicas e comerciais; crise da dívida externa; crise fiscal do Estado; elevadas inflações; juros altos e um baixo crescimento econômico. Assim sendo, tais fragilidades e o próprio subdesenvolvimento da região criaram um cenário difícil de se ajustar diante da globalização neoliberal, o que indicava acuradamente um risco elevado de crises econômicas.

27 Segundo Espíndola (2019), a situação econômica que a América Latina herdou nos anos de 1980 era tão desesperadora que tal fato pode ser observado a partir dos dados da Comissão Econômica para a América Latina e o Caribe [CEPAL $]^{1}$ ao expor que em 1970 o PIB regional era de 5,6\% ao ano, caindo para 1,2\% na década de 1980 . Além disso, a recessão econômica continuou de tal modo que entre 1981 e 1990 a média do PIB per capita foi de 0,6\% e a dívida externa da região alcançou USD 332,3 bilhões de dólares (MUNHOZ, 2002 apud ESPÍNDOLA, 2019).

28 Espíndola (2019) explana que o governo dos Estados Unidos junto ao FMI, temendo que a situação na região do Cone-Sul fosse sair do controle, implementaram medidas como políticas fiscais e monetárias restritivas, assim como a desvalorização cambial, cujo objetivo era fomentar as exportações e ao mesmo tempo diminuir as importações. Por conseguinte, reforça-se que tais medidas não tiveram o efeito positivo esperado, levando a um agravamento da recessão econômica dos países da América Latina, o que também significava que novas medidas teriam que ser implantadas na região. Deste modo, na década de 1980, as novas providências foram chamadas de o "Consenso de Washington" (ESPÍNDOLA, 2019).

29 Assim sendo, de acordo com o FMI, Banco Mundial, Congresso dos Estados Unidos e algumas autoridades do banco central cmericano, a meta do Consenso de Washington era estabilizar as economias latino americanas através de ajustes fiscais e políticas ortodoxas - para que estas integrassem a ordem econômica neoliberal e globalizada através de dez medidas. Martins (2011) apud Pessoa e Leal (2019) expõem as medidas como:
1. Disciplina fiscal;
2. Gastos com saúde, educação e infraestrutura seriam prioridades;
3. Reforma tributária;
4. Liberalização financeira;
5. Taxa de câmbio competitiva;
6. Queda de barreiras tarifárias para a liberalização comercial;
7. Abertura a investimentos diretos estrangeiros;
8. Privatização de empresas públicas;
9. Forte desregulamentação da economia;
10. Proteção à propriedade privada. 
As dez medidas estavam alinhadas com o fenômeno da Globalização, já que esta demandava uma abertura dos mercados e das economias nacionais ao Sistema Internacional; adequação aos preços internacionais; aumento das exportações; garantia dos direitos à propriedade privada; mínima regulação do Estado na economia; entre outros (SANTOS, 2002 apud PESSOA e LEAL, 2019).

31 Após o implemento do Consenso de Washington, a década de 1990 e começo dos anos 2000 seriam marcados por mais expectativas do que realizações. Assim, conforme apresentado anteriormente, as medidas tinham como objetivo o combate ao subdesenvolvimento da região da América Latina. Todavia, apesar de parecer ser um caminho a seguir, a situação que a região viria a passar, negativamente, seria os estopins de crises econômicas generalizadas - conforme a Tabela 1.

Tabela 1. As crises econômicas da década de 1990 e início dos anos 2000

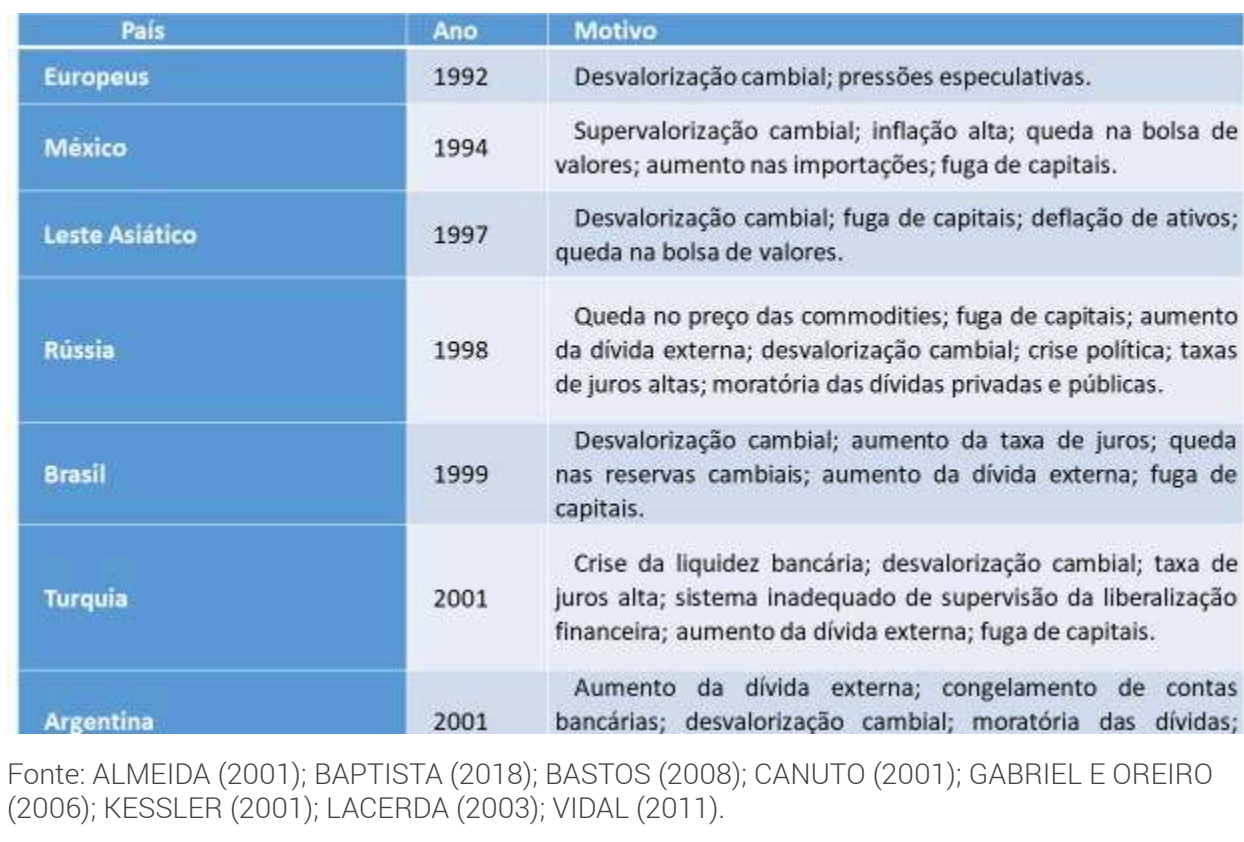

De acordo com os dados expostos na Tabela 1 é possível averiguar como a década de 1990 e início dos anos 2000 foram marcados pelo advento de crises econômicas de alcance mundial. Além de poder observar o efeito contágio das crises, há causas comuns que levaram ao estopim dos eventos. Nos dados acima, fica claro que os países, além da América Latina, não foram capazes de seguir as medidas do Consenso de Washington, o que provava que o neoliberalismo globalizado e financeiro era extremamente frágil.

Baptista (2018) explica que na década de 1990 os países da América Latina buscaram atrelar suas moedas nacionais ao dólar como uma proteção ao controle de capitais, visto que a moeda não sofria grandes variações cambiais e que atraia investimentos estrangeiros em mercados subdesenvolvidos. A flutuação cambial eram uma medida a ser evitada, pois qualquer oscilação geraria desconfianças e inadimplências no mercado de capitais, o que, por conseguinte, poderia causar uma fuga maciça de capitais. Entretanto, com o acirramento da competição internacional e da própria complexidade do mundo globalizado, as taxas de câmbio fixas parecem ir de encontro com a integração financeira mundial (BAPTISTA, 2018). 

na ruptura da paridade com o dólar, ou seja, quando o país começa a utilizar das flutuações cambiais e a desregulamentação financeira - que podem causar fuga de capitais e desequilíbrios estruturais das balanças comerciais. Os países, principalmente os periféricos, não iriam ter a possiblidade de manter por muito tempo a paridade com o dólar como uma unidade de referência das finanças internacionais, visto que a inserção e competição internacional seriam totalmente desvantajosas (TAVARES e METRI, 2020).

Diante desse cenário, o Estado, já defasado pela crise econômica, não tinha muito o que fazer, pois de acordo com as doutrinas neoliberais, este interveria parcialmente no mercado e na economia. Em suma, sua participação não seria nada mais do que um complemento do mercado, cujas ações tinham o objetivo de facilitar a liberalização financeira e o desenvolvimento mercadológico (ROCHA e CABRAL, 2018). crise econômica, o subdesenvolvimento da região latina americana colocava também em xeque a atuação da globalização produtiva, ou seja, os países não podiam contar com as produções nacionais e nem mesmo com as ações, por exemplo, de empresas transnacionais para conter o efeito contágio das crises. Deste modo, a única solução encontrada foi a utilização de recursos da globalização financeira. o estopim das crises econômicas da década de 1990. O que se observa é que mesmo após o advento das crises, a continuidade da utilização da financeirização se tornou a única saída dos países, principalmente aqueles em desenvolvimento. A lógica era que se os Estados não tinham recursos produtivos suficientes para se inserirem no mercado internacional, então a utilização da liberalização financeira se tornou a peça fundamental para um esperado crescimento econômico.

Segundo Tavares e Metri (2020) o final do século XX se caracterizou não apenas por uma expansão dos fluxos comerciais mundiais, mas também dos fluxos financeiros. No caso dos países periféricos, a globalização financeira criou um cenário complexo para que estes pudessem sobreviver, visto que os mesmos se inseriram no sistema internacional como receptores de capitais especulativos, muito por conta de não possuírem internamente tecnologias ou recursos tangíveis para incentivar uma produção interna.

39 Os países periféricos passaram a dar mais prioridade aos recursos da globalização financeira do que a globalização produtiva, como o capital especulativo ${ }^{2}$. Muitos dos países latino americanos, por exemplo, eram dependentes de investimentos estrangeiros, o que, por conseguinte, os levaram a financiar suas contas correntes com a especulação financeira. Mais do que isso, este capital é muito sensível a emergência de crises econômicas, sendo que seu estopim gerou uma fuga maciça de capitais, levando aos países a utilizarem de mecanismos como flutuações cambiais ou taxa de juros para contornar tal crise (OLIVEIRA e SILVA, 2016). Entretanto, a utilização de taxas flutuantes acarreta graves desequilíbrios na economia nacional e inibem o crescimento econômico.

Segundo os dados do Fundo Monetário Internacional, entre 1992 e 2001, o crescimento médio do PIB mundial foi de 3,23\%, enquanto no mesmo período a América Latina cresceu apenas 2,89\%. Neste cenário, os reflexos das crises econômicas podem ser 
observados na região latino americano ao averiguar que entre 1992 e 2001 o saldo da conta corrente, em porcentagem do PIB, foi de $-2,92 \%$, evidenciando assim os desequilíbrios econômicos (FMI, 2020).

41 A ascensão de crises econômicas na década de 1990 veio reafirmar o significado da globalização, ou seja, um mundo interconectado onde eventos isolados geram efeitos colaterais em escala mundial. Apesar de as crises econômicas do final do século XX terem ocorrido em diferentes escopos geográficos, seu efeito dominó não tardou a acontecer e o mundo inteiro sentiu os efeitos negativos em suas economias nacionais.

A globalização financeira neoliberal deixou o mundo ainda mais vulnerável, o que também significava que o Consenso de Washington falhou com suas dez medidas, que não foram adequadas para a realidade do mundo globalizado em si. A queda das barreiras nacionais, assim como a interconectividade dos mercados e dos fluxos financeiros, permitiu o efeito contágio de crises econômicas. Além disso, a sobreposição da globalização financeirasobre a globalização produtiva deixou as economias nacionais extremamente frágeis e vulneráveis a qualquer externalidade.

\section{0 advento da pandemia Coronavírus em 2020 e seus impactos na economia global neoliberal}

No final do ano de 2019, a Organização Mundial da Saúde [OMS] recebeu um alerta sobre uma estranha e inesperada onda de pneumonia na cidade de Wuhan, província de Hubei, na China. Assim sendo, a pneumonia identificada era na verdade um novo tipo de vírus, sem histórico de identificação em seres humanos - chamado de coronavírus (ORGANIZAÇÃO PAN-AMERICANA DA SAÚDE, 2020).

44 Segundo a Organização Mundial da Saúde [OMS] (2020) o coronavírus advém de uma grande família de vírus que pode causar doenças em animais ou humanos - sendo neste último infecções respiratórias que variam desde um resfriado comum até doenças mais graves, como a Síndrome Respiratória Aguda Grave (SARS). Deste modo, no começo de janeiro de 2020, as autoridades chinesas confirmaram que a pneumonia era causada por um novo coronavírus, dentro dos seis já identificados, e que era chamado de SARSCoV-2, cuja doença causada era o COVID-19 (ORGANIZAÇÃo PAN-AMERICANA DA SAÚDE, 2020).

A OMS (2020) também vai definir o COVID-19 como a doença infeciosa causada pelo sétimo coronavírus SARS-CoV-2, cujos sintomas mais comuns são: febre; cansaço e tosse seca, podendo evoluir para dores; congestão nasal; corrimento nasal; dor de garganta ou diarreia. 0 meio de transmissão da doença são pessoas que têm o vírus, visto que o COVID-19 pode se espalhar de pessoa para pessoa quando esta tosse ou exala (ORGANIZAÇÃO PAN-AMERICANA DA SAÚDE, 2020).

46 A Universidade Johns Hopkins (2020) averigua que no final de janeiro de 2020, já havia aproximadamente 10.000 casos confirmados de coronavírus na China, além de alguns casos confirmados em outros países como Tailândia, Japão, Austrália, Estados Unidos, França, dentre outros. Deste modo, a disseminação do SARS-CoV-2 não tardou a acontecer em escala mundial, já que no dia 29 de fevereiro o total de pessoas contaminadas com o coronavírus era de aproximadamente 86.000 e no dia 12 de março eram 131.000. (UNIVERSIDADE JOHNS HOPKINS, 2020). 
47 Por conseguinte, a OMS, através do $51^{\circ}$ relatório de situação, declarou que a doença COVID-19 era caracterizado como uma "pandemia" ${ }^{3}$ - muito devido aos surtos ocorrerem em várias localizações geográficas, onde novos surtos isolados acabavam por disseminar em países terceiros (ORGANIZAÇÃO MUNDIAL DA SAÚDE, 2020).

Senhoras (2020) explica que o surto do conoravírus causa impactos econômicos assimétricos, pois variam de acordo com o nível de sensibilidade e vulnerabilidade dos países, mas que em escala global afetam a macroeconomia dos Estados e a microeconomia das cadeias mundiais de produção e consumo. Averígua-se que um tempo mais lento de reação diante do coronavírus causará impactos negativos cada vez maiores, tanto nos seres humanos quanto nas economias mundiais (SENHORAS, 2020). Ora, enquanto a economia mundial parece estar caminhando para uma forte recessão economia, no dia 20 de abril de 2020 havia no mundo 2.314 .621 casos confirmado de COVID-19 e 157.847 mortes (ORGANIZAÇÃO PAN-AMERICANA DA SAÚDE, 2020).

49 Segundo as avaliações de Senhoras (2020), os efeitos a curto prazo da pandemia na economia global serão:

- Desabastecimento microeconômico das produções nacionais e do mercado consumidor;

- Falência de pequenas e médias empresas;

- Congelamento das atividades de Empresas Multinacionais;

- Aumento do desemprego;

- Restrições ao comércio exterior, turismo e aviação civil;

- Fuga e queda do mercado de capitais;

- Diminuição dos investimentos diretos estrangeiros.

50 O autor ainda afirma que no longo prazo o resultado da constrição dos fluxos produtivos levará a:

- Crescimento Internacional negativo;

- Desaceleração e desequilíbrios das economias globais.

51 De acordo com o Monitor de Comércio de Investimento (2020) da Conferência das Nações Unidas sobre Comércio e Desenvolvimento [UNCTAD], os países ao redor do mundo vêm sofrendo com uma drástica redução dos Investimentos Diretos Estrangeiros [IDE]. Tal fato ocorre devido aos choques negativos das demandas e as interrupções das cadeias globais de suprimento. Deste modo, a UNCTAD prevê que entre 2020 e 2021 a pressão descendente sobre o IDE será entre -5\% e -15\% (CONFERÊNCIA DAS NAÇÕES UNIDAS SOBRE COMÉRCIO E DESENVOLVIMENTO, 2020).

52 Além disso, a UNCTAD (2020) explica que com o mundo caminhando para uma possível recessão econômica mundial, as empresas multinacionais estão diminuindo suas despesas de capital com o objetivo de tentar sobreviver no curto prazo, o que, por conseguinte, acarreta uma diminuição nos lucros e nos reinvestimentos em diversos setores da economia. Assim, uma média feita pela UNCTAD com as 5.000 maiores empresas multinacionais demonstrou que o lucro total obtido em 2020 será apenas de $9 \%$, e que as industriais automobilísticas sofrerão com - $44 \%$; cias aéreas $-42 \%$ e energia e materiais básicos industriais -13\% (CONFERÊNCIA DAS NAÇÕES UNIDAS SOBRE COMÉRCIO E DESENVOLVIMENTO, 2020).

53 Segundo a Fundação Getúlio Vargas (2020), o Índice de Confiança do Comércio [ICOM] monitora e antecipa as tendências econômicas comércio e, assim, em março de 2020 já foi averiguado que o índice caiu 11,7 pontos - sendo ocasionado pela preocupação dos empresários com relação aos negócios diante do CoVID-19. 

UNCTAD (2020), desde o surto do coronavírus o mercado de commodities vem sofrendo uma baixa em seus preços, como por exemplo o petróleo, metais, produtos minerais, agrícolas, e que possivelmente até o final do ano poderão sofrer com um declínio de preço em $37 \%$. Todavia, é previsto que ocorra algumas pequenas exceções na queda dos preços das commodities, como por exemplo a produção agrícola com uma queda de $-6,8 \%$ e de metais preciosos 5\% (CONFERÊNCIA DAS NAÇõES UNIDAS SOBRE COMÉRCIO E DESENVOLVIMENTO, 2020). de uma pandemia acarreta uma grande fuga de capitais nacionais, regionais e multilaterais, o que, consequentemente, a vulnerabilidade da financeirização se dá pelas quedas dos preços na bolsas de valores. Mais do que isso, com o capital saindo de um determinado país, este irá procurar mecanismos de ações de contenção, como a flutuação cambial, que gerará um ciclo vicioso de recessão econômica em escala mundial.

Em suma, um cenário que é possível esperar para o futuro próximo é a retomada das crises econômicas dos anos 1990. Conforme exposto anteriormente, no final século XX, os países se mostraram extremamente vulneráveis a Globalização, sendo que aqueles que deram ênfase no mercado financeiro acima da produção, puderam observar a 
fragilidade da financeirização em si. Bastou que eventos isolados levassem a uma significativa fuga de capitais, gerando um efeito contágio negativo em países e regiões terceiras do globo.

No momento atual, principalmente após o surto do Coronavírus, a tese das crises cíclicas está se reafirmando, visto que a pandemia expôs a vulnerabilidade e a sensibilidade dos países no Sistema Internacional. Presentemente, os Estados que possuem mais capital especulativo do que produtivo são os que mais irão sofrer com os efeitos colaterais negativos do vírus - visto que não poderão contar com suas indústrias nacionais para equilibrar o jogo do mercado capitalista consumista, ou seja, a oferta e a demanda.

Após a disseminação do COVID-19, as bolsas de valores ao redor do mundo estão quase entrando em colapso, visto a queda brusca dos preços das ações, o que caracteriza alguns países como um grau de risco alta de inadimplência e possível falência econômica, levando os investimentos a serem redirecionados a localizações geográficas mais seguras. Somado a isso, sem as produções nacionais para compensar as perdas do capital especulativo, os Estados serão obrigados a utilizar das flutuações cambiais, aumentos e cortes da taxa de juros, aumento da dívida externa, esgotamento das reservas internacionais, moratórias, dentro outros, com o objetivo de sobreviver a curto prazo.

63 Tais medidas são causas de recessões econômicas, conforme averiguadas na Figura 1. Assim, já é possível averiguar, atualmente, que os países diante da pandemia do coronavírus estão revivendo o mesmo cenário das crises econômicas dos anos 1990 . Todavia, era de se esperar que as crises do passado tivessem levado aos Estados a compreenderem a volatilidade do mercado de capitais, assim como a globalização financeira. Resumindo, era de se esperar que em momentos de crise os países tivessem recursos e investimentos nacionais sólidos de modo a suprir quaisquer externalidades no cenário global.

Figura 1.0 crescimento anual do PIB e do Saldo da Conta Corrente em relação ao PIB (\%) diante de crises econômicas e do surto do Coronavírus.

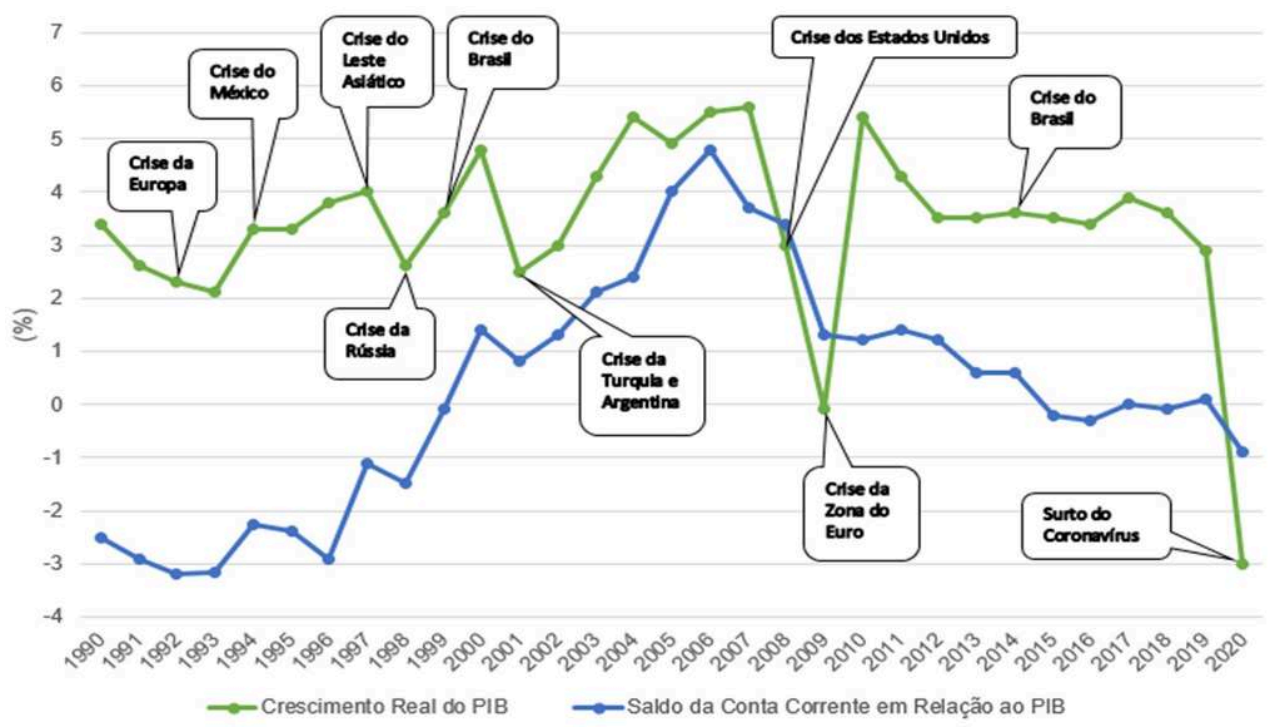

Fonte: Elaborado a partir do FUNDO MONETÁRIO INTERNACIONAL (2020); BANCO MUNDIAL (2020) 

movimento do capital e das commodities são protegidas pelas regras e instituições da ordem econômica do neoliberalismo. Afirma-se que a doutrina neoliberal parece não ter se ajustado ao sistema internacional, visto que desde a sua implantação as atividades do setor público diminuíram enquanto as do setor privado subiram significativamente, incluindo do mercado de ações, pela busca de lucro (LUCCHESE e PIANTA, 2020).

70 Assim, a pandemia do coronavírus dramaticamente expôs como as políticas neoliberais parecem frágeis, visto que a globalização financeiracriou um mercado incapaz de responder a qualquer emergência ou externalidade (LUCCHESE e PIANTA, 2020). Além disso, explica-se que o fato de a globalização produtiva e o setor público ter ficado em 
segundo plano gerou desequilíbrios nacionais, gerando disparidades políticas e socioeconômicas. Os Estados que mais investem em capital especulativo são os que mais estão propensos a perecer, já que as doutrinas nacionais levam a baixas taxas de crescimento econômico, desequilíbrios políticos, baixos ganhos produtivos, disparidades sociais, etc. (LUCCHESE e PIANTA, 2020).

71 Desde as crises econômicas dos anos 1990, ficou claro que a hegemonia do capital financeiro não seria a única solução dos anos por vir. Contudo, os Estados preferem utilizar deste recurso, já que a possiblidade de se obter lucro ocorre a curto prazo. Segundo Oliveira e Silva (2016), a acumulação do capital financeiro fez com que as produções nacionais apresentassem baixa rentabilidade, muito devido a mudança do foco de investimento produtivo para o mercado financeiro, gerando assim uma estagnação econômica.

Oliveira e Silva (2016) explanam que diante da globalização financeira, o capital especulativo não é sinônimo de crescimento econômico, pois este não gera aumento das carteiras de trabalho assinadas e nem de renda. Tecnicamente, o uso desse capital poderia sim promover um desenvolvimento da economia nacional, desde que o Estado criasse mecanismos não apenas para sua entrada, mas também para sua permanência. Deste modo, caberia ao país criar políticas macroeconômicas que tornariam o desenvolvimento pouco sustentável, porém sem uma educação política e econômica adequada, haveria a possibilidade de instabilidades econômicas (OLIVEIRA e SILVA, 2016).

De acordo com Belluzo e Galípodo (2017), os Estados nacionais não estão interessados em criar tais políticas macroeconômicas. A partir de 1990, o capitalismo se reestruturou de tal modo ante a gobalização que este criou um cenário de grande concorrência internacional, onde sobreviver era o objetivo comum. Assim, o mundo globalizado se caracteriza por esse acirramento da concorrência entre as corporações transnacionais; sociedade e Estados que estão presente em um mundo comandado pela estrutura financeira, mais especificamente comandada pela dolarização.

O mundo que inaugurou o século XXI viveu sob a égide do capital financeiro, que criou uma grande estrutura de controle e tomada de decisões, que subjugou e fragmentou a globalização produtiva com o objetivo de lucrar mais rapidamente (Belluzo e Galípodo, 2017). Exemplifica-se que, atualmente, nos Estados Unidos o valor de empréstimos bancários para as instituições financeiras é considerado quatro vezes maior do que empréstimos destinados a criação de empregos e renda, ou seja, há uma maior busca por dividendos e juros sobre o capital próprio do que investimentos em unidades fabris e na contratação de pessoas (BELLUZO e GALÍPODO, 2017).

75 É possível averiguar o por que a globalização financeira possui uma maior atividade dentro dos países do que a globalização produtiva. Também, observa-se que apesar da alta participação do mercado financeiro no sistema internacional, este se mostrou muito frágil diante de qualquer tipo de externalidade - o que gera danos econômicos a curto e longo prazo. Ao que tudo indica, o neoliberalismo falhou ao permitir a liberalização financeira sem barreiras, pois não são todos os Estados que contam com um sistema financeiro adequado; sólido e que sabe repartir os investimentos nas produções nacionais.

76 Assim sendo, o cenário de desequilíbrios políticos e socioeconômicos que o mundo está passando desde janeiro de 2020, com o surto da pandemia do COVID-19, é apenas um reflexo do que foi a crise econômica dos anos 1990. Nas duas últimas décadas, os 
Estados ainda continuaram a desviar foco de seus investimentos para o mercado financeiro que é extremamente volátil, o que apenas elevou a vulnerabilidade e sensibilidade dos países. Tal fato expõe como a globalização financeira neoliberal não está ajustada as verdadeiras diretrizes e necessidades do mundo globalizado, o que, cada vez mais, acarretará cenários negativos e com um efeito contágio contínuo e irreparável.

\section{Conclusão}

O surto do coronavírus e a disseminação da doença COVID-19 colocou qualquer expectativa política e/ou socioeconômica positiva, para o ano de 2020, em questão. Em 1994, Eric Hobsbawm em seu livro "A Era dos Extremos", ao explicar as causas da segunda guerra mundial (1939-1945), chamou os países formadores do eixo, como a Alemanha, Itália e Japão, de o "Inimigo Comum". É irônico de se pensar que em pleno século XXI o mundo mais uma vez compartilharia um novo inimigo comum, porém de caráter microbiológico, cuja disseminação e efeitos também acontecem em escala mundial.

Desde 1990, os países, principalmente aqueles em desenvolvimento, viram a globalização financeiracomo uma oportunidade de competir no cenário internacional e obter lucros mais rapidamente. 0 problema é que tal prática se tornou tão comum que os Estados acabaram colocando suas produções nacionais em segundo plano, ou seja, investiu-se mais no mercado financeiro do que nas produções nacionais. Em suma, a globalização financeirase sobrepôs à globalização produtiva.

Os anos de 1990, com o estopim de crises econômicas, expuseram que a escolha dos Estados pela financeirização do capital deixou suas soberanias nacionais frágeis e vulneráveis a qualquer externalidade - visto a volatilidade do mercado financeiro. Era de se esperar que os países tivessem visto as crises econômicas do passado como uma possibilidade de aprendizado, levando futuramente a um equilíbrio dos focos de investimentos. Todavia, não foi o que aconteceu.

Desde a crise econômica dos países europeus em 1992 até a pandemia do coronavírus em 2020, pode-se observar que os Estados estão presos em crises cíclicas nas quais não conseguem sair. Tal pandemia não apenas prova como a globalização financeiraé vulnerável, mas também como o próprio neoliberalismo o é. Os primeiros efeitos de uma suposta crise econômica mundial em 2020 é também fruto de uma crise da doutrina neoliberal, que aparentemente não soube ajustar suas diretrizes para o mundo globalizado, muito menos para os países periféricos.

81 A possiblidade de transações financeiras internacionais; as flutuações cambiais; diminuição do papel de Estado; etc., como parte da doutrina neoliberal, deixou os países muito vulneráveis perante a globalização, visto que diante de externalidades suas produções nacionais não viriam a suprir as demandas do capitalismo e o país não teria condições suficientes para conter os desequilíbrios nacionais.

Mesmo sendo uma externalidade microbiológica, o surto do coronavírus mais uma vez expôs a fragilidade da globalização financeira neoliberal, trazendo à tona as más experiências do passado. Aparentemente, os Estados não mudaram suas doutrinas nacionais de modo a sobreviver no sistema internacional por um longo prazo. Assim, o COVID-19, diante desse cenário, causará em 2020 e possivelmente em 2021 uma drástica queda no PIB. Os países utilizarão medidas como flutuações cambiais; aumento e corte 
da taxa de juros; pacotes de empréstimos, etc., que no curto prazo, além de conter os desequilíbrios nacionais, gerará uma significativa recessão econômica em escala mundial.

Diante do coronavírus, ficou claro que a gobalização é uma porta aberta para o efeito contágio de externalidades, seja positivo ou negativo. Infelizmente, o mundo chegou num ponto em que se questiona a funcionalidade do neoliberalismo e a sustentabilidade da globalização financeira. É bem provável que no futuro surjam novos "inimigos comuns", contudo dependerá, única e exclusivamente, da vontade dos Estados em mudar as doutrinas nacionais e internacionais, e que os permitirão sobreviver neste Sistema Internacional tão incerto, complexo e interconectado.

\section{BIBLIOGRAFIA}

ALMEIDA, Paulo Roberto de. O Brasil e as crises financeiras internacionais, 1929-2001. Revista Cena Internacional, 3, pp. 89-114, 2001.

ATUALIZAÇÃO DO RELATÓRIO DE COMÉRCIO E DESENVOLVIMENTO DA CONFERÊNCIA DAS NAÇÕES UNIDAS SOBRE COMÉRCIO E DESENVOLVIMENTO [UNCTAD]. 1-12 [2020] - O choque do Covid-19 para os países em desenvolvimento: rumo a um programa "o que for preciso" para os dois terços da população mundial serem deixados para trás. <https://unctad.org/en/ PublicationsLibrary/gds_tdr2019_covid2_en.pdf $>$. Acessado em 13 abril de 2020.

BANCO MUNDIAL [BM]. Crescimento anual do PIB. [2020], <https://data.worldbank.org/ indicator/NY.GDP.MKTP.KD.ZG>. Acesso em: 18 abr. 2020.

BAPTISTA, Livia Nalesso. Desequilíbrios globais e crises financeiras: história, teorias e evidências. Programa de Pós-graduação em Economia, Universidade Federal de Uberlândia, 153p., 2018.

BASTOS, Luciana Aparecida. Avaliação do desempenho comercial do Mercosul: 1995-2005. Programa de Pós-graduação em História Econômica, Universidade de São Paulo, 158p., 2008.

BELLUZZO, Luiz Gonzaga; GALÍPOLO, Gabriel. Globalizaçãodesigual e combinada. Revista Texto para Discussão, pp. 1-35, 2017.

BELLUZO, Luiz Gonzaga; ANTUNES, Davi Nardy. O poder real. [2015], <http:// www.cartacapital.com.br/revista/875/o-poder-real-2372.html>. Acessado em 30 de julho de 2020.

BRESSER-PEREIRA, Luiz Carlos. A reforma, do estado dos anos 90: logica e mecanismos de controle. Revista Lua Nova, 45, pp. 49-95, 1998.

CANUTO, Otaviano. A crise asiática e seus desdobramentos: causas, consequências e recuperação. Revista Econômica, 2, pp. 25-60, 2001.

CAVALCANTI, André Luiz Cordeiro. Ensaios sobre globalização, crescimento econômico e distribuição de renda. Programa de Pós-graduação em Economia, Universidade de Brasília, 114p., 2019.

COMISSÃO ECONÔMICA PARA A AMÉRICA LATINA E O CARIBE [CEPAL]. (2020). Sobre a CEPAL. [2020], <https://www.cepal.org/pt-br/cepal-0>. Acessado em 13 abril de 2020. 
ESPÍNDOLA, Carlos José. Considerações sobre os determinantes do desenvolvimento econômico da América Latina: dos anos de 1980 ao início do século XXI. Revista Pantaneira, 16, pp. 28-42, 2019.

FORNASIER, Mateus de Oliveira; SOARES, Fabricio Zambra. Globalizaçãoe meios adequados de solução de conflitos: da importância da arbitragem para as empresas transnacionais. Revista Eletrônica de Direito Processual, 21, pp. 335-367, 2020.

FUNDO MONETÁRIO INTERNACIONAL [FMI]. Crescimento real do PIB. [2020], <https:// www.imf.org/external/datamapper/NGDP_RPCH@WEO/OEMDC/ADVEC/WEOWORLD>. Acessado em 14 abril de 2020.

FUNDO MONETÁRIO INTERNACIONAL [FMI]. Saldo da conta corrente, porcentagem do PIB. [2020], <https://www.imf.org/external/datamapper/BCA_NGDPD@WEO/OEMDC/>. Acessado em 18 abril de 2020.

FUNDAÇ̃̃o GETÚLIO VARGAS [FGV]. Sondagem do comércio. [2020], <https://portalibre.fgv.br/ data/files/E8/F4/E0/72/B0F01710199794F68904CBA8/

Sondagem\%20do\%20Com_rcio\%20FGV_press\%20release_Mar20.pdf>. Acessado em 15 abril de 2020.

GABRIEL, Luciano Ferreira OREIRO, José Luís. A crise financeira e cambial da Turquia em 2001 e a sua recuperação econômica. Revista Economia e Tecnologia, 6, pp. 127-134, 2006.

GONÇALVES, Antonio Baptista. Diplomacia e o século XXI: os desafios da globalização. Caderno de Relações Internacionais, 9, pp. 201-246, 2018.

HONÓRIO, Nathan Gálicos Ferreira; GUERRA, José Alfredo de Pádua. Globalizaçãofinanceira: a influência da taxa de juros frente ao investimento estrangeiro especulativo no brasil. Revista Eletrônica de Debates em Economia, 1, pp. 259-no. 1 (2012): 259-323.

KESSLER, Timothy. A quebra do peso mexicano: causas, consequências e recuperação. Revista de Economia Política, 21, pp. 121-145, 2011.

LACERDA, Antônio Corrêa de. Globalizaçãoe inserção externa da economia brasileira: política econômica, investimentos diretos estrangeiros e comércio exterior, na década de 1990. Instituto de Economia, Universidade Estadual de Campinas, 198p., 2003.

LUCCHESE, Matteo; PIANTA, Mario. The Coming Coronavirus Crisis: What Can We Learn? Journal Intereconomics, 55, pp. 98-104, 2020.

MONITOR DE COMÉRCIO DE INVESTIMENTO DA CONFERÊNCIA DAS NAÇÕES UNIDAS SOBRE COMÉRCIO E DESENVOLVIMENTO [UNCTAD]. Impacto do surto do coronavirus no ide global. [2020], <https://unctad.org/en/PublicationsLibrary/diaeinf2020d2_en.pdf>. Acessado em 13 de abril de 2020.

OLIVEIRA, Larissa Regina Arruda de; SILVA, Jose Alderir da. A desindustrialização e o capital especulativo na economia brasileira. Revista Indicadores Economicos FEE, 44, pp. 45-60, 2016.

ORGANIZAÇÃO PAN-AMERICANA DA SAÚDE [OPAS]. Folha informativa - COVID-19 (doença causada pelo novo coronavírus). [2020], <https://www.paho.org/bra/index.php? option=com_content\&view=article\&id=6101:covid19\&Itemid=875>. Acessado em 13 de abril de 2020.

ORGANIZAÇÃO MUNDIAL DA SAÚDE [OMS]. Perguntas e respostas sobre o Coronavírus (COVID-19). [2020], <https://www.who.int/news-room/q-a-detail/q-a-coronaviruses>. Acessado em 14 de abril de 2020. 
PESSOA, Sara de Araújo; LEAL, Jackson da Silva. GlobalizaçãoHegemônica e Política Criminal Neoliberal. Revista de Direito e Praxis, 10, pp. 2620-2640, 2019.

ROCHA, Rosaly Justiniano de Souza; CABRAL, José Pedro Cabrera. Neoliberalismo e programas de transferências monetárias condicionadas na américa latina. Revista de História Comparada, 12, pp. 234-267, 2018.

SENHORAS, Elói Martins. Novo coronavírus e seus impactos econômicos no mundo. Revista Boletim de Conjuntura, 1, pp. 39-42, 2020.

TAVARES, Maria Da Conceição; METRI, Mauricio. A geoeconomia do império e as mutações do capital: os dois ciclos de expansão econômica dos Estados Unidos no final do século XX. Revista de Economia Política, 40, pp. 3-21, 2020.

THORSTENSEN, Vera et al. o quadro regulatório do sistema financeiro internacional. Working Paper, 518, pp. 1-23, 2019.

UNIVERSIDADE JOHNS HOPKINS. Rastreando dados críticos. [2020], <https:// coronavirus.jhu.edu/data\#charts>. Acessado em 14 de abril de 2020.

VIDAL, Tatiana Ladeira. Crises financeiras: efeito contágio ou interdependência? Evidências utilizando uma abordagem multivariada. Programa de Pós-Graduação em Administração, Universidade de São Paulo, 175p., 2011.

\section{NOTAS}

1. A CEPAL é uma Organização Internacional criada em 1948 com o objetivo de contribuir para o desenvolvimento da região latino-americana e os países do Caribe, assim como coordenar as relações econômicas internacionais dos países entre si e com terceiros (CEPAL, 2020).

2. O capital especulativo pode ser definido como aquele que não é produtivo e cujos ganhos ocorrem na esfera financeira, sem obrigação de permanência no país de destino (CARCANHOLO e NAKATANI, 1999 APUD OLIVEIRA e SILVA, 2016).

3. De acordo com a OPAS, o termo "pandemia", declarado no dia 11 de março pela OMS, se refere a disseminação geográfica de uma determinada doença, visto seu alastramento em escala mundial (ORGANIZAÇÃO PAN-AMERICANA DA SAÚDE, 2020).

\section{RESUMOS}

O objetivo deste artigo é analisar como a pandemia do Coronavírus afetou negativamente as economias nacionais, em grande parte por conta da fragilidade dessas economias diante da financeirização do capital, ou seja, a globalizaçãofinanceira. o resultado de uma revisão bibliográfica sobre o tema apontou para a hipótese de que diante da volatilidade do mercado financeiro, os países irão reviver cenários semelhantes aos das crises econômicas da década de 1990, causando uma forte recessão econômica em 2020.

El propósito de este artículo es analizar cómo la pandemia del Coronavirus ha afectado negativamente a las economías nacionales, en gran parte por la fragilidad de estas economías 
ante la financiarización del capital, es decir, la Globalización Financiera. El resultado de una revisión de la literatura sobre el tema apuntó a la hipótesis de que ante la volatilidad del mercado financiero, los países reactivarán escenarios similares a los de las crisis económicas de los años noventa, provocando una fuerte recesión económica en 2020

The purpose of this article is to analyze how the Coronavirus pandemic has negatively affected national economies, largely because of the fragility of these economies in the face of the financialization of capital, that is, financial globalization. The result of a literature review on the topic pointed to the hypothesis that in the face of the volatility of the financial market, countries will revive scenarios similar to those of the economic crises of the 1990s, causing a strong economic recession in 2020 .

Le but de cet article est d'analyser comment la pandémie de coronavirus a affecté négativement les économies nationales, en grande partie à cause de la fragilité de ces économies face à la capitalisation financière, c'est-à-dire la mondialisation financière. Le résultat d'une revue de la littérature sur le sujet a fait ressortir l'hypothèse que face à la volatilité du marché financier, les pays vont relancer des scénarios similaires à ceux des crises économiques des années 1990, provoquant une forte récession économique en 2020.

\section{ÍNDICE}

Palavras-chave: globalizaçãofinanceira, globalizaçãoprodutiva, crises econômicas, neoliberalismo, coronavírus.

Palabras claves: globalización financiera, globalización productiva, crisis económicas, neoliberalismo, coronavirus.

Mots-clés: globalisation financière, globalisation productive, crise économique, néolibéralisme, coronavirus.

Keywords: financial globalization, productive globalization, economic crisis, neoliberalism, coronavirus.

\section{AUTOR}

\section{PEDRO HENRIQUE CHINAGLIA}

Pós-Graduado MBA em Gestão de Negócios pela Escola Superior de Agricultura Luiz de Queiroz (ESALQ/USP) 